\title{
Tolerability of Oxaliplatin-based Neoadjuvant Chemoradiotherapy in Elderly Locally Advanced Rectal Cancer Patients: A Case-control Study of a Real-life Experience
}

\author{
FRANCESCA DE FELICE, BENEDETTA SINISCALCHI, NADIA BULZONETTI, \\ ROSSELLA CAIAZZO, DANIELA MUSIO and VINCENZO TOMBOLINI
}

Department of Radiotherapy, Policlinico Umberto I, "Sapienza" University of Rome, Rome, Italy

\begin{abstract}
Background/Aim: The aim of this study was to delineate clinical criteria to safely select elderly patients who can benefit from adding oxaliplatin to 5-fluoruracil-based neo-adjuvant chemoradiotherapy (CRT) in locally advanced rectal cancer (LARC) management. Patients and Methods: This is a single-institutional case-control study on LARC patients who received intensified neo-adjuvant CRT, between January 2007 and December 2014. Data concerning patient characteristics, treatment details and adverse events were reviewed and analyzed in two settings: young patients $(<65$ years) and elderly ( $\geq 65$ years). A binary logistic model was applied to analyze the potential interaction between clinical variables and severe toxicity risk. Results: In total, 100 consecutive LARC patients were included. Mean age was 63.6 years and $55 \%(n=55)$ of the patients had adult comorbidity evaluation-27 (ACE-27) score $\geq 1$. Most cancers $(81 \%)$ were lymph node positive at diagnosis. Overall, $\geq 5$ cycles of oxaliplatin were administered to 92 patients (92\%). Only 17 patients (17\%) reported grade $\geq 3$ toxicity. The elderly group did not experience significantly higher severe toxicity than the young group. ACE-27 score $\geq 1$ was the only variable independently associated with a higher severe toxicity. The 5-year overal survival (OS) rates were $64.1 \%$ and $89.2 \%$ in the elderly and young cohort, respectively. Conclusion: Elderly LARC patients can be safely treated with intensified neo-adjuvant CRT.
\end{abstract}

Correspondence to: Francesca De Felice, Department of Radiotherapy, Policlinico Umberto I, "Sapienza" University of Rome, Viale Regina Elena 326, Rome, Italy. Tel: +39 0649973411, Fax: +39 0649973411, e-mail: fradefelice@hotmail.it

Key Words: Elderly, rectal cancer, oxaliplatin, toxicity, chemoradiotherapy, neo-adjuvant treatment, survival.
With the increase in aging population, geriatric oncology has gained increasing attention within research community. Over the years, locally advanced rectal cancer (LARC) diagnosis has gradually increased in elderly and its management still remains crucial, especially due to potential age-related vulnerability (1-2). At present, the trimodality approach, including a combination of chemoradiotherapy (CRT), total mesorectal excision (TME) surgery and chemotherapy (CHT), is the recommended strategy to assure a curative intent goal (3). Considering that systemic recurrences represent the main treatment failure, several intensification CRT regimens have been tested and the use of oxaliplatin as radiation-sensitizing agent seems to be a plausible option (4). Adding oxaliplatin to standard 5-fluoruracil-based CRT is related to significant clinical benefit in term of distant failure (4). However, whether the addition of oxaliplatin to neoadjuvant CRT is well-tolerated remains to be determined. In this scenario, clinical criteria to adequately select elderly patients who can profit from oxaliplatin in a safe manner are needed.

The purpose of this single-institution study was to assess the tolerability of adding oxaliplatin to standard CRT, as well as to identify possible predictors of developing oxaliplatinrelated toxicity in elderly LARC patients.

\section{Patients and Methods}

Patient population. We retrospectively reviewed a prospectively maintained database of patients with histological proven adenocarcinoma of the rectum, staged tumor (T) 3-4 and/or with nodes $(\mathrm{N})$ involved at diagnosis, treated with an intensified neoadjuvant treatment between January 2007 and December 2014. This case-control study was approved by the institutional review board (Prot. 464/16) and the scientific review committee. The following clinical data were collected by chart review: patient demographics (age, gender and race), patient characteristics [performance status (PS), smoking history, hepatic and renal 
function, comorbidities], tumor stage at diagnosis, treatment modality and compliance (dose reduction, treatment discontinuation, number of CHT cycles administered), treatment-related toxicity and follow-up. To classify patient comorbidities, the adult comorbidity evaluation-27 (ACE-27) score was used (5). Whereas, toxicity was scored according to the common terminology criteria for adverse events, version $4.0(6)$.

Neo-adjuvant treatment. All patients received a trimodality approach with curative intent, including intensified neo-adjuvant CRT, followed by surgery and adjuvant CHT. Details were described in our previous series $(7,8)$. RT was delivered to a total dose of $45 \mathrm{~Gy}$ in 25 fractions to the whole pelvis, plus 5.4 to $9 \mathrm{~Gy}$ in 3 to 5 fractions to the tumor volume. Concomitant CHT consisted of oxaliplatin $50 \mathrm{mg} / \mathrm{m}^{2}$ on the first day of each week of RT and 5fluoruracil $200 \mathrm{mg} / \mathrm{m}^{2} /$ day of each week of RT. Surgery was planned from 7 to 9 weeks after the end of CRT. Surgical approach was left to surgeon's discretion. Adjuvant chemotherapy regimen was chosen by the oncologist.

Statistical analysis. Standard descriptive statistics were used to evaluate the distribution of each factor. Categorical variables were compared using the chi-square or Fisher's exact test. Continuous variables were dichotomized. Statistical tests were two-sided. A $p$ value $<0.05$ was considered statistically significant in the tests. In order to identify potential predictors of toxicity from oxaliplatin, the following variables were investigated: advanced age $(<65$ years versus $\geq 65$ years), PS (0 versus $\geq 1)$, renal impairment - defined as creatinine serum level $>1.1 \mathrm{mg} / \mathrm{dl}$ - (no versus yes), ACE-27 score ( 0 versus $\geq 1$ ), polypharmacy - defined as the concomitant use of $\geq 2$ drugs - (no versus yes), cycles of oxaliplatin ( $\leq 5$ versus $>5$ ), CRT interruption (no versus yes). Based on age category, two groups were defined: young patients $<65$ years and elderly patients with $\geq 65$ years. Treatment-related toxicities were analyzed according to this patient age cut-off value. A binary logistic model was applied to determine the effect of independent variables on severe toxicity risk.

Overall survival (OS) and disease-free survival (DFS) rates were estimated by the Kaplan-Meier method and curves were compared by the log-rank test. Both OS and DFS were calculated in months from the end of CRT to the first event, including date of the last follow-up or death (OS) and/or relapse (DFS). Statistical analysis was carried out using R-Studio 0.98.1091 software.

\section{Results}

Patient characteristics. Overall, 100 patients were eligible for this study. Patient and tumor baseline characteristics are presented in Table I. Mean age was 63.6 years (range $=38-76$ years) and 51 patients aged $\geq 65$ years (elderly group). The most common clinical symptom at diagnosis was rectal bleeding $(n=61 ; 61 \%)$. The vast majority of patients $(n=81$, $81 \%$ ) had regional lymph node involvement and stage distribution at diagnosis was homogeneous among young and old patients. Overall, $45(45 \%)$ patients had no comorbidity and did not assume any drug. Most patients $(\mathrm{n}=55 ; 55 \%)$ had ACE-27 score $\geq 1$. In the elderly group, a higher frequency of ACE-27 score $\geq 2$ was recorded compared to the young cohort (10 versus 3, $p=0.05$ ). Whereas, there was no statistically significant difference in creatinine serum levels between elderly patients and young groups $(p=0.59)$. Hypertension was the most reported comorbidity $(n=41,41 \%)$.

Neo-adjuvant treatment-related toxicity. All patients completed the programmed CRT. The majority of patients $(\mathrm{n}=92,92 \%)$ received intensified neoadjuvant CRT with oxaliplatin and 5-fluoruracil for $\geq 5$ cycles. Chemotherapy was definitely suspended in 8 patients. These patients received less than 5 cycles of oxaliplatin and all but one were elderly (Table II). None patients in both groups discontinued due to worsening of pre-existing comorbidities. All patients had CRT-related toxicity. Details are shown in Table III. No significant differences in the type and number of both acute and late toxicities were recorded between age groups. Overall, the most frequent acute adverse event was proctitis $(n=71,71 \%)$. Interestingly, only 17 patients $(17 \%)$ reported grade 3 toxicity. Of these cases, 11 patients (64.7\%) were elderly. but incidence was not statistically different compared to younger $(p=0.24)$. Venous thromboembolic event (VTE) occurred in 11 patients (11\%). The overall VTE incidence was slightly higher, but not statistically significant $(p=0.44)$ in elderly patients $(\mathrm{n}=7,63.6 \%)$ compared to young patients $(n=4,36.4 \%)$. A logistic regression was performed based on these variables with a statistically significant difference between elderly and young patients, to evaluate their association to severe toxicity onset (Table IV). Only ACE-27 score $\geq 1$ was independently associated with a higher risk of developing severe toxicity $(\mathrm{OR}=2.13,95 \% \mathrm{CI}=1.28$ $8.32 ; p=0.05)$. Interestingly, being older than 65 years of age was not related to a worst toxicity grade $(\mathrm{OR}=0.56$, $95 \% \mathrm{CI}=0.19-2.03 ; p=0.25)$.

Survival outcomes. In total, 20 patients died, of whom 15 in the elderly group. Five-year OS and 5-year DFS rates for the entire population were $76.4 \%(95 \% \mathrm{CI}=0.642-0.848)$ and $74.5 \%$ (95\% CI $=0.616-0.836$ ), respectively. According to age, 5 -year OS was $64.1 \%(95 \% \mathrm{CI}=0.45-0.78)$ for elderly patients and $89.2 \%(95 \% \mathrm{CI}=0.73-0.96)$ in the young group $(p=0.04)$. Whereas, the 5-year DFS was similar between the two groups $(52.6 \%, 95 \% \mathrm{CI}=0.36-0.67$ versus $57.7 \%, 95 \% \mathrm{CI}=0.41-0.72$; $p=0.81$ ). Details are listed in Figures 1 and 2.

\section{Discussion}

This real-life study revealed that adding oxaliplatin to standard 5-fluoruracil-based CRT was not associated with an increase in severe toxicity risk in LARC elderly patients. Severe toxicity was predominantly related to ACE-27 score $\geq 1$, whereas age per se was not a predictive factor of adverse events. 
Table I. Patient and tumor baseline characteristics.

\begin{tabular}{|c|c|c|c|c|}
\hline Characteristic & Total $(\%)$ & Young $(\%)$ & Elderly $(\%)$ & $p$-Value \\
\hline \multicolumn{5}{|l|}{ Age (years) } \\
\hline Mean (range) & $63.6(38-76)$ & $56.6(38-64)$ & $70.2(65-76)$ & \\
\hline Gender & & & & 0.25 \\
\hline Male & $67(67)$ & $30(61)$ & $37(72)$ & \\
\hline Female & $33(33)$ & $19(39)$ & $14(28)$ & \\
\hline Performance status & & & & 0.37 \\
\hline 0 & $98(98)$ & $49(100)$ & $49(96)$ & \\
\hline$\geq 1$ & $2(2)$ & $0(0)$ & $2(4)$ & \\
\hline ACE-27 score & & & & 0.05 \\
\hline 0 & $45(45)$ & $22(45)$ & $23(45)$ & \\
\hline 1 & $42(42)$ & $24(49)$ & $18(35)$ & \\
\hline$\geq 2$ & $13(13)$ & $3(6)$ & $10(20)$ & \\
\hline Comorbidities & & & & 0.62 \\
\hline Hypertension & 41 & $16(33)$ & $25(49)$ & \\
\hline Diabetes mellitus & 11 & $5(10)$ & $6(12)$ & \\
\hline Gastro-intestinal disease & 8 & $7(14)$ & $1(2)$ & \\
\hline Creatinine serum level & & & & 0.59 \\
\hline Mean (sd) & $0.76(+/-0.15)$ & $0.74(+/-0.14)$ & $0.79(+/-0.21)$ & \\
\hline Polypharmacy & & & & 0.05 \\
\hline No & 87 & $46(94)$ & $41(80)$ & \\
\hline Yes & 13 & $3(6)$ & $10(20)$ & \\
\hline Symptom at diagnosis & & & & 0.26 \\
\hline Rectal bleeding & $61(61)$ & $27(55)$ & $34(67)$ & \\
\hline Constipation/diarrhea & $22(22)$ & $13(27)$ & $9(18)$ & \\
\hline Asthenia & $17(17)$ & $9(18)$ & $8(15)$ & \\
\hline Clinical tumor stage $(\mathrm{T})$ & & & & 0.91 \\
\hline$\leq \mathrm{T} 3$ & $77(77)$ & $38(78)$ & $39(76)$ & \\
\hline $\mathrm{T} 4$ & $23(23)$ & $11(22)$ & $12(24)$ & \\
\hline Clinical nodal stage $(\mathrm{N})$ & & & & 0.17 \\
\hline Negative & $19(19)$ & $12(24)$ & $7(14)$ & \\
\hline Positive & $81(81)$ & $37(76)$ & $44(86)$ & \\
\hline
\end{tabular}

sd: Standard deviation.

These clinical results are consistent with the recently published expert recommendations of the European Society of Surgical Oncology, European Society of Coloproctology, International Society of Geriatric Oncology, and American College of Surgeons Commission on Cancer regarding the modern management of rectal cancer in elderly patients (9). A personalized treatment, based on patient frailty rather than his/her chronological age, has been highlighted in order to guarantee the best possible multimodal approach and, therefore, the greatest outcomes (9). At present, an adequate co-morbidity evaluation should be integrated in routine clinical practice to identify those patients who need further health status assessment. Actually, different chart-based comorbidity instruments are available in the literature, but there is no consensus on the optimal one (10-12). We selected the ACE-27 tool because it evaluates at the same time several important comorbid conditions, such as dementia, diabetes mellitus and body weight that are not all together considered in the others (5).
Table II. Treatment compliance.

\begin{tabular}{lcccc}
\hline Variable & Total (\%) & Young (\%) & Elderly (\%) & $p$-Value \\
\hline Cycles of oxaliplatin & & & & 0.04 \\
$\quad 55$ & 8 & 1 & 7 & \\
$\quad 5$ & 92 & 48 & 44 & \\
CRT interruption & & & & 0.35 \\
No & 84 & 43 & 41 & \\
Yes & 16 & 6 & 10 & \\
\hline
\end{tabular}

Also, the ACE-27 tool permits to classify the cogent comorbid ailment on a range of important options and grade severity in order to identify a score with overall discriminative performance. We considered this characteristic as a relevant point for us to support our choice of an intensified multimodal approach. According to the current trend (13), the results of this study provide evidence to define therapy on biological 
Table III. Acute and late toxicity.

\begin{tabular}{|c|c|c|c|c|c|c|c|}
\hline \multirow[b]{2}{*}{ Toxicity } & \multicolumn{2}{|c|}{ Total } & \multicolumn{2}{|c|}{ Young } & \multicolumn{2}{|c|}{ Elderly } & \multirow[b]{2}{*}{$p$-Value* } \\
\hline & G1-2 (\%) & $\mathrm{G} \geq 3(\%)$ & $\mathrm{G} 1-2(\%)$ & $\mathrm{G} \geq 3(\%)$ & G1-2 (\%) & $\mathrm{G} \geq 3(\%)$ & \\
\hline \multicolumn{8}{|l|}{ Acute } \\
\hline \multicolumn{8}{|l|}{ Allergy immunology } \\
\hline Allergic reaction hypersensitivity & $6(6)$ & - & $5(10)$ & - & $1(2)$ & - & \\
\hline \multicolumn{8}{|l|}{ Constitutional symptoms } \\
\hline Fatigue & $18(18)$ & - & $5(10)$ & - & $13(25)$ & - & \\
\hline Fever & $10(10)$ & - & $6(12)$ & - & $4(8)$ & - & \\
\hline Palpitation & $1(1)$ & - & $1(2)$ & - & - & - & \\
\hline \multicolumn{8}{|l|}{ Dermatology skin } \\
\hline Rash desquamation & $10(10)$ & - & $4(8)$ & - & $6(12)$ & - & \\
\hline Radiation dermatitis & $31(31)$ & $3(3)$ & $17(35)$ & - & $14(27)$ & $3(6)$ & 0.18 \\
\hline \multicolumn{8}{|l|}{ Gastrointestinal } \\
\hline Constipation/diarrhoea & $49(49)$ & $4(4)$ & $20(41)$ & $2(4)$ & $29(57)$ & $2(4)$ & \\
\hline Nausea/vomiting & $24(24)$ & - & $18(37)$ & - & $6(12)$ & - & \\
\hline Proctitis & $68(68)$ & $6(6)$ & $35(71)$ & $1(2)$ & $33(65)$ & $5(10)$ & 0.16 \\
\hline \multicolumn{8}{|l|}{ Neurology } \\
\hline Neuropathy: sensory & $20(20)$ & $1(1)$ & $7(14)$ & $1(2)$ & $13(25)$ & - & 0.25 \\
\hline \multicolumn{8}{|l|}{ Pain } \\
\hline Abdominal pain or cramping & $13(13)$ & $2(2)$ & $7(14)$ & $1(2)$ & $6(12)$ & $1(2)$ & 0.75 \\
\hline \multicolumn{8}{|l|}{ Renal genitourinary } \\
\hline Dysuria & $26(26)$ & - & $11(22)$ & - & $15(29)$ & - & \\
\hline Urinary frequency & $4(4)$ & - & $1(2)$ & - & $3(6)$ & - & \\
\hline \multicolumn{8}{|l|}{ Blood count } \\
\hline Haemoglobin & $1(1)$ & $1(1)$ & $1(2)$ & - & - & $1(2)$ & 0.75 \\
\hline \multicolumn{8}{|l|}{ Late } \\
\hline \multicolumn{8}{|l|}{ Gastrointestinal } \\
\hline Constipation/diarrhoea & $11(11)$ & - & $5(10)$ & - & $6(12)$ & - & \\
\hline Fecal incontinence & $15(15)$ & - & $6(12)$ & - & $9(18)$ & - & \\
\hline Proctitis & $14(14)$ & - & $9(18)$ & - & $5(10)$ & - & \\
\hline \multicolumn{8}{|l|}{ Pain } \\
\hline Abdominal pain or cramping & $2(2)$ & - & $2(4)$ & - & - & - & \\
\hline \multicolumn{8}{|l|}{ Dermatology skin } \\
\hline Radiation dermatitis & $3(3)$ & - & $1(2)$ & - & $2(4)$ & - & \\
\hline \multicolumn{8}{|l|}{ Neurology } \\
\hline Neuropathy: sensory & $6(6)$ & - & $5(10)$ & - & $1(2)$ & - & \\
\hline \multicolumn{8}{|l|}{ Renal genitourinary } \\
\hline Dysuria & $1(1)$ & - & - & - & $1(2)$ & - & \\
\hline \multicolumn{8}{|l|}{ Reproductive system } \\
\hline Sexual dysfunction & $7(7)$ & - & $4(8)$ & - & $3(6)$ & - & \\
\hline \multicolumn{8}{|l|}{ Vascular disorders } \\
\hline Venous thromboembolism & - & $11(11)$ & - & $4(8)$ & - & $7(14)$ & 0.44 \\
\hline
\end{tabular}

*referred to severe toxicity.

aging. Despite the addition of oxaliplatin, in our study, severe toxicity rate was relative low $(17 \%)$ and in any case equal to or better than previously published studies; both randomized studies, that tested oxaliplatin in the neoadjuvant setting (from $23 \%$ up to $40 \%$ ) (14-17), and in a retrospective elderly series (from $12 \%$ up to $35 \%$ ) (18-20). Even if oxaliplatin is probably responsible for improving toxicity incidence, it is well-known that oxaliplatin mainly causes neurotoxic adverse events due to cell death in neural ganglia of the dorsal spinal nerve root
(21). We recorded 21 patients (21\%) with peripheral neuropathy and $71 \%$ of these patients $(n=15)$ showed complete recovery several months after oxaliplatin infusion. Interestingly, there was only one patient (1\%) with acute severe neurological toxicity, whereas none experienced grade 3 sensory neuropathy in the long term. These rates are somewhat lower than those reported in the ACCORD 12/0405 - PRODIGE 02 trial, in which late peripheral neuropathy was described in 22 patients $(3.8 \%)$, including 14 cases of grade 


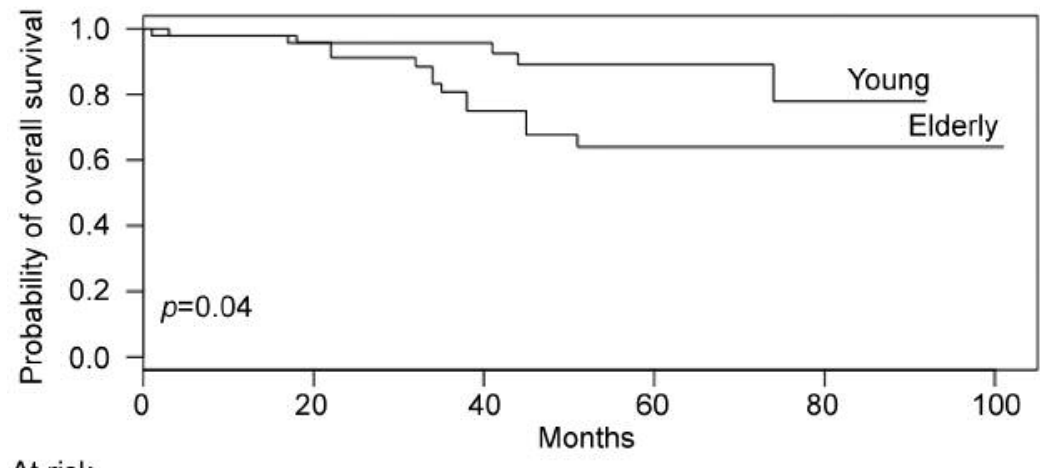

$\begin{array}{llllll}\text { At risk } & & & & & \\ \text { Young } & 49 & 43 & 31 & 27 & 8 \\ \text { Elderly } & 51 & 46 & 28 & 18 & \end{array}$

Figure 1. Overall survival according to age group.

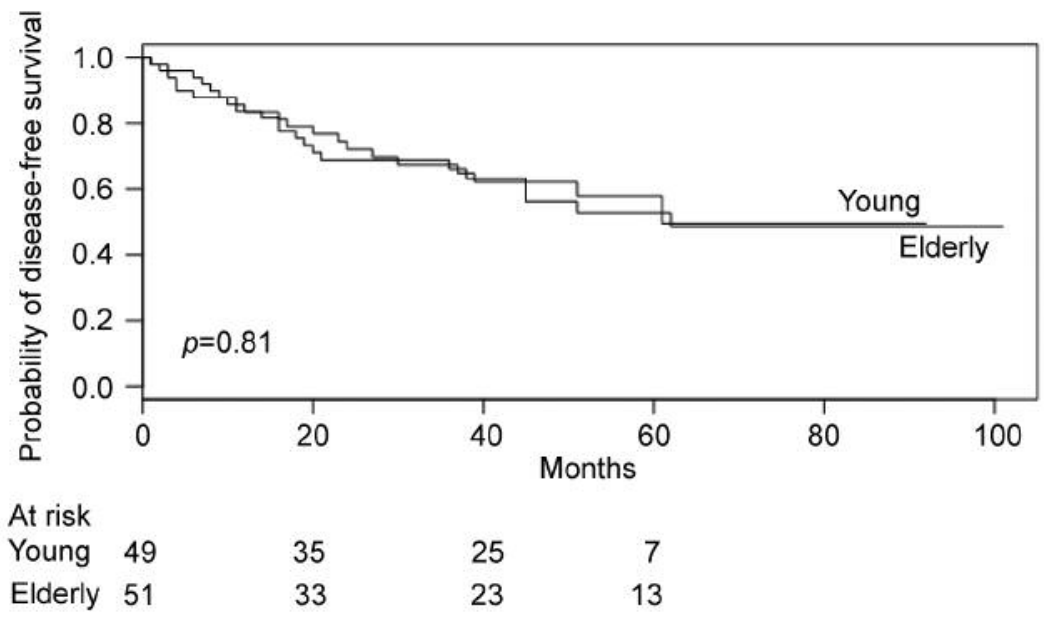

Figure 2. Disease-free survival according to age group.

1, 5 cases of grade 2 and 3 cases of grade 3 (22). To note, to our knowledge, except for the ACCORD 12/0405 - PRODIGE 02 trial, data on late toxicity from phase III trials exploring the efficacy of the addition of oxaliplatin to standard CRT are still not available. In this context, our study suggests that probably oxaliplatin regimen $-50 \mathrm{mg} / \mathrm{m}^{2}$ once a week - is a safe dosage able to potentially maintain therapeutic effectiveness without increasing severe acute and late toxicity, even in elderly.

This study has several limitations, mainly due to its retrospective observational nature. Firstly, it was not possible to examine causal relationships between variables. Secondly, considering that we were unable to control over factors that might have influenced treatment decision-making, our data
Table IV. Logistic regression of factors predictive of severe toxicity.

\begin{tabular}{lcc}
\hline Prognostic factor & OR $(95 \% \mathrm{CI})$ & $p$-Value \\
\hline Age $\geq 65$ & $0.56(0.19-2.03)$ & 0.25 \\
ACE-27 score $\geq 1$ & $2.13(1.28-8.32)$ & 0.05 \\
Polypharmacy & $1.61(0.24-5.72)$ & 0.53 \\
Cycles of oxaliplatin $\geq 5$ & $0.81(0.27-8.25)$ & 0.31 \\
\hline
\end{tabular}

could underestimate the relative risk of oxaliplatin use. This study remains hypothesis-generating and therefore final results should be confirmed in a prospective trial. Surely, over the years, evaluation of health status is becoming more 
popular in oncologic literature. This study provides evidence in favour of specific tests to determine a personalized cancer care in those LARC patients with severe co-morbidities.

\section{Conclusion}

Our study suggested that adding oxaliplatin to neo-adjuvant treatment should be considered safe and manageable, even in the elderly population. ACE-27 score might be of help to establish the risk of CRT-related toxicities. Further studies on geriatric populations are expected to further personalize LARC treatment in these patients.

\section{Conflicts of Interest}

All Authors declare that they have no conflicts of interest that might be relevant to the contents of this manuscript.

\section{Authors' Contributions}

FDF, BS, NB, RC and DM have made substantial contributions to the conception of the work, the acquisition and interpretation of data and have drafted the work; VT has substantively revised it. All Authors have approved the submitted version.

\section{References}

1 Bray F, Ferlay J, Soerjomataram I, Siegel RL, Torre LA and Jemal A: Global cancer statistics 2018: GLOBOCAN estimates of incidence and mortality worldwide for 36 cancers in 185 countries. CA Cancer J Clin 68(6): 394-424, 2018. PMID: 30207593. DOI: $10.3322 /$ caac. 21492

2 Rutten HJ, den Dulk M, Lemmens VE, van de Velde CJ and Marijnen CA: Controversies of total mesorectal excision for rectal cancer in elderly patients. Lancet Oncol 9(5): 494-501, 2008. PMID: 18452860. DOI: 10.1016/S1470-2045(08)70129-3

3 National Comprehensive Cancer Network Guidelines, Rectal Cancer, Version 3.2018. Available at: https://www.nccn.org (Last accessed 04/11/2019)

4 De Felice F, Benevento I, Magnante AL, Musio D, Bulzonetti $\mathrm{N}$, Caiazzo $\mathrm{R}$ and Tombolini V: Clinical benefit of adding oxaliplatin to standard neoadjuvant chemoradiotherapy in locally advanced rectal cancer: a meta-analysis: Oxaliplatin in neoadjuvant treatment for rectal cancer. BMC Cancer 17(1): 325, 2017. PMID: 28499428. DOI: 10.1186/s12885-017-3323-4

5 Piccirillo JF, Tierney RM, Costas I, Grove L and Spitznagel EL Jr: Prognostic importance of comorbidity in a hospital-based cancer registry. JAMA 291(20): 2441-2447, 2004. PMID: 15161894. DOI: 10.1001/jama.291.20.2441

6 Cancer Therapy Evaluation Program. Common terminology criteria for adverse events, version 5.0 2017, Available at: http://ctep.cancer.gov (Last accessed 04/11/2019)

7 De Felice F, Musio D, Magnante AL, Bulzonetti N, Benevento I, Caiazzo R and Tombolini V: Disease control, survival, and toxicity outcome after intensified neoadjuvant chemoradiotherapy for locally advanced rectal cancer: A Single-Institution Experience. Clin Colorectal Cancer 15(2): e17-22, 2016. PMID: 26952656. DOI: 10.1016/j.clcc.2016.02.006
8 Musio D, De Felice F, Bulzonetti N, Guarnaccia R, Caiazzo R, Bangrazi C, Raffetto $\mathrm{N}$ and Tombolini V: Neoadjuvantintensified treatment for rectal cancer: time to change? World J Gastroenterol 19(20): 3052-3061, 2013. PMID: 23716984. DOI: 10.3748/wjg.v19.i20.3052

9 Montroni I, Ugolini G, Saur NM, Spinelli A, Rostoft S, Millan M, Wolthuis A, Daniels IR, Hompes R, Penna M, Fürst A, Papamichael D, Desai AM, Cascinu S, Gèrard JP, Myint AS, Lemmens VEPP, Berho M, Lawler M, De Liguori Carino N, Potenti F, Nanni O, Altini M, Beets G, Rutten H, Winchester D, Wexner SD and Audisio RA: Personalized management of elderly patients with rectal cancer: Expert recommendations of the European Society of Surgical Oncology, European Society of Coloproctology, International Society of Geriatric Oncology, and American College of Surgeons Commission on Cancer. Eur J Surg Oncol 44(11): 1685-1702, 2018. PMID: 30150158. DOI: 10.1016/j.ejso.2018.08.003

10 Kaplan MH and Feinstein AR: The importance of classifying initial co-morbidity in evaluating the outcome of diabetes mellitus. J Chronic Dis 27(7-8): 387-404, 1974. PMID: 4436428. DOI: 10.1016/0021-9681(74)90017-4

11 Charlson ME, Pompei P, Ales KL and MacKenzie CR: A new method of classifying prognostic comorbidity in longitudinal studies: development and validation. J Chronic Dis 40(5): 373-383, 1987. PMID: 3558716. DOI: 10.1016/00219681(87)90171-8

12 Greenfield S, Apolone G, McNeil BJ and Cleary PD: The importance of co-existent disease in the occurrence of postoperative complications and one-year recovery in patients undergoing total hip replacement. Comorbidity and outcomes after hip replacement. Med Care 31(2): 141-54, 1993. PMID: 8433577. DOI: 10.1097/00005650-199302000-00005

13 Schmoll HJ, Van Cutsem E, Stein A, Valentini V, Glimelius B, Haustermans K, Nordlinger B, van de Velde CJ, Balmana J, Regula J, Nagtegaal ID, Beets-Tan RG, Arnold D, Ciardiello F, Hoff P, Kerr D, Köhne CH, Labianca R, Price T, Scheithauer W, Sobrero A, Tabernero J, Aderka D, Barroso S, Bodoky G, Douillard JY, El Ghazaly H, Gallardo J, Garin A, Glynne-Jones R, Jordan K, Meshcheryakov A, Papamichail D, Pfeiffer P, Souglakos I, Turhal S and Cervantes A: ESMO Consensus Guidelines for management of patients with colon and rectal cancer. a personalized approach to clinical decision making. Ann Oncol 23(10): 2479-2516, 2012. PMID: 23012255. DOI: 10.1093/annonc/mds236

14 Gérard JP, Azria D, Gourgou-Bourgade S, Martel-Laffay I, Hennequin C, Etienne PL, Vendrely V, François E, de La Roche G, Bouché O, Mirabel X, Denis B, Mineur L, Berdah JF, Mahé MA, Bécouarn Y, Dupuis O, Lledo G, MontotoGrillot $\mathrm{C}$ and Conroy $\mathrm{T}$ : Comparison of two neoadjuvant chemoradiotherapy regimens for locally advanced rectal cancer: results of the phase III trial ACCORD 12/0405-Prodige 2. J Clin Oncol 28: 1638-1644, 2010. PMID: 20194850. DOI: 10.1200/JCO.2009.25.8376

15 Rödel C, Liersch T, Becker H, Fietkau R, Hohenberger W, Hothorn T, Graeven U, Arnold D, Lang-Welzenbach M, Raab HR, Sülberg H, Wittekind C, Potapov S, Staib L, Hess C, Weigang-Köhler K, Grabenbauer GG, Hoffmanns H, Lindemann F, Schlenska-Lange A, Folprecht G, Sauer R and German Rectal Cancer Study Group: Preoperative chemoradiotherapy and postoperative chemotherapy with fluorouracil and oxaliplatin versus 
fluorouracil alone in locally advanced rectal cancer: initial results of the German CAO/ARO/AIO-04 randomised phase 3 trial. Lancet Oncol 13: 679-687, 2012. PMID: 22627104. DOI: 10.1016/S1470-2045(12)70187-0

16 O'Connell MJ, Colangelo LH, Beart RW, Petrelli NJ, Allegra CJ, Sharif S, Pitot HC, Shields AF, Landry JC, Ryan DP, Parda DS, Mohiuddin M, Arora A, Evans LS, Bahary N, Soori GS, Eakle J, Robertson JM, Moore DF Jr, Mullane MR, Marchello BT, Ward PJ, Wozniak TF, Roh MS, Yothers G and Wolmark N: Capecitabine and oxaliplatin in the preoperative multimodality treatment of rectal cancer: surgical end points from National Surgical Adjuvant Breast and Bowel Project trial R-04. J Clin Oncol 32: 1927-1934, 2014. PMID: 24799484. DOI: 10.1200/ JCO.2013.53.7753

17 Aschele C, Cionini L, Lonardi S, Pinto C, Cordio S, Rosati G, Artale S, Tagliagambe A, Ambrosini G, Rosetti P, Bonetti A, Negru ME, Tronconi MC, Luppi G, Silvano G, Corsi DC, Bochicchio AM, Chiaulon G, Gallo M and Boni L: Primary tumor response to preoperative chemoradiation with or without oxaliplatin in locally advanced rectal cancer: pathologic results of the STAR-01 randomized phase III trial. J Clin Oncol 29(20): 2773-2780, 2011. PMID: 21606427. DOI: 10.1200/JCO.2010. 34.4911

18 Tougeron D, Roullet B, Paillot B, Hamidou H, Tourani JM, Bensadoun RJ, Michel P and Silvain C: Safety and outcome of chemoradiotherapy in elderly patients with rectal cancer: results from two French tertiary centres. Dig Liver Dis 44(4): 350-354, 2012. PMID: 22119617. DOI: 10.1016/j.dld.2011.10.017

19 Guimas V, Boustani J, Schipman B, Lescut N, Puyraveau M, Bosset JF and Servagi-Vernat S: Preoperative chemoradiotherapy for rectal cancer in patients aged 75 years and older: acute toxicity, compliance with treatment, and early results. Drugs Aging 33(6): 419-425, 2016. PMID: 27138958. DOI: 10.1007/ s40266-016-0367-0
20 Cai X, Wu H, Peng J, Zhu J, Cai S, Cai G and Zhang Z: Tolerability and outcomes of radiotherapy or chemoradiotherapy for rectal cancer in elderly patients aged 70 years and older. Radiat Oncol 8: 86, 2013. PMID: 23574985. DOI: 10.1186/ 1748-717X-8-86

21 Nagata T, Fukuda KI, Tamai M, Taniguchi A, Kamiya H, Kambe K, Kamada Y, Iwata G and Yamaoka N: Early neuropathy related to oxaliplatin treatment in advanced and recurrent colorectal cancer. Anticancer Res 39(3): 1347-1353, 2019. PMID: 30842168. DOI: 10.21873/anticanres.13248

22 Azria D, Doyen J, Jarlier M, Martel-Lafay I, Hennequin C, Etienne P, Vendrely V, François E, de La Roche G, Bouché O, Mirabel X, Denis B, Mineur L, Berdah J, Mahé M, Bécouarn Y, Dupuis O, Lledo G, Seitz J, Bedenne L, Gourgou-Bourgade S, Juzyna B, Conroy $\mathrm{T}$ and Gérard J: Late toxicities and clinical outcome at 5 years of the ACCORD 12/0405-PRODIGE 02 trial comparing two neoadjuvant chemoradiotherapy regimens for intermediate-risk rectal cancer. Ann Oncol 28(10): 2436-2442, 2017. PMID: 28961836. DOI: 10.1093/annonc/mdx351
Received October 30, 2019

Revised November 4, 2019

Accepted November 6, 2019 